\title{
BIOFERTILIZANTE E ADUBAÇÃO MINERAL NO DESENVOLVIMENTO DA CULTURA DA CEBOLA (ALLIUM CEPA L.) IRRRIGADO COM DUAS LÂMINAS DE ÁGUA
}

NOBILE, Fabio Olivieri de ${ }^{1}$ GALBIATTI, João Antonio ${ }^{2}$ MURAISHI, Reginaldo Itiro ${ }^{3}$ SPADONI, Thais Botamede ${ }^{4}$

RESUMO: Com a finalidade de se quantificar os efeitos de diferentes níveis de água, adubação orgânica (efluente de biodigestor) e adubação mineral sobre o desenvolvimento da cultura de cebola (Allium cepa L.), realizou-se a presente pesquisa no Departamento de Engenharia Rural da FCAV/UNESP- SP/Brasil. Para alcançar os objetivos propostos, submeteu-se a cultura de cebola a diferentes níveis de água, fazendo-se também uso da adubação orgânica (na dose de $60 \mathrm{~m}^{3}$ há ${ }^{-1}$ ) e mineral (convencional), para efeito de comparação. A partir dos dados obtidos, levantaram-se valores referentes à altura das plantas, diâmetro médio de bulbos, produção por planta e por hectare e potencial matricial da água no solo. Da análise dos resultados, concluiu-se que a adubação mineral da cebola pode ser substituída pela adubação orgânica (origem bovina), efluente de biodigestor. Os níveis de água correspondentes a 100 e 150\% da evapotranspiração máxima considerada, são os ideais para o desenvolvimento da cultura, e a adubação orgânica manteve o solo com potencial matricial mais alto que a aplicação de adubo mineral para todos os níveis de água aplicados.

Palavras-chave: Efluente. Biodigestor. Evapotranspiração. Saneamento.

SUMMARY: In order to quantify the effects of different levels of water, organic fertilization (effluent of biodigestor) and mineral fertilizer on the development of culture of onion (Allium cepa L.), was held on this research in the Departamento de Engenharia Rural da FCAV/UNESP- SP / Brazil. To achieve the proposed objectives, referred to the cultivation of onion at different levels of water, is also making use of organic manure (in the dose of $60 \mathrm{~m}^{3} \mathrm{ha}^{-1}$ ) and mineral (conventional), for purposes of comparison. From the data obtained, raised up figures for the plant height, average diameter of bulbs, and plant production per hectare and matric potential of water in the soil. The analysis of results, it was concluded that the mineral fertilization of onion can be replaced by organic fertilization (bovine), effluent of biodigestor. The levels of water corresponding to 100 and $150 \%$ of the maximum considered evapotranspiration, are ideal for the development of culture, organic fertilizer and kept the soil with the highest potential matrix that the application of mineral fertilizer for all levels of water applied.

Keywords: Effluent. Biodigestor. Evapotranspiration. Sanitation.

\section{INTRODUÇÃO}

$\mathrm{Na}$ agricultura irrigada é fundamental o conhecimento das necessidades hídricas das culturas. De acordo com Lopes et. al. (2008), com o acelerado crescimento populacional mundial e a busca por melhor qualidade de vida das populações, surge, a cada dia, a necessidade de maior produção de alimentos. Com isso, expandiram-se as áreas agricultáveis em todo o mundo, impulsionando, então, o uso da irrigação, não só como complemento das necessidades hídricas das regiões úmidas, mas também como opção de tornar produtivas as regiões áridas e semi-áridas do planeta. Ongley (2000) afirma que, com a expansão das áreas irrigadas, crescem também os problemas de degradação dos recursos naturais (solo e água), principalmente aqueles relacionados à salinidade e à sodicidade do solo. Fachini, et al. (2004) trabalhando

\footnotetext{
${ }^{1}$ Centro Universitário da Fundação Educacional de Barretos - UNIFEB

${ }^{2}$ Universidade Estadual Paulista - UNESP - Jaboticabal

${ }^{3}$ Centro Universitário da Fundação Educacional de Barretos - UNIFEB

${ }^{4}$ Centro Universitário da Fundação Educacional de Barretos - UNIFEB
} 
com níveis de irrigação e de composto de lixo orgânico na formação de mudas cítricas em casa de vegetação, constataram a variação nos valores da necessidade de água com os diferentes estádios de desenvolvimento e tipos de substratos para as mudas. Já Marquelli et al. (2002) verificaram a redução do desenvolvimento, produtividade comercial, tamanho médio de bulbos e a eficiência do uso de água em até $70 \%, 63 \%, 31 \%$ e 57\%, respectivamente, quando plantas de alho foram submetidas à deficiência hídrica, em qualquer dos estádios vegetativos.

O cultivo intensivo com emprego de doses elevadas de fertilizantes minerais eleva, temporariamente, a capacidade produtiva do solo, mas, em médio ou longo prazo, pode conduzi-lo à degradação, se a matéria orgânica mineralizada não for reposta (NOBILE, 2009; KIEHL 1985).

Quanto mais degradado, o solo apresenta menores respostas às adubações minerais, fazendo-se necessária a adição também de materiais orgânicos com a finalidade de corrigir as propriedades físicas alteradas pelos cultivos (NOBILE et al., 2008).

Quando resíduos orgânicos são decompostos, ativam os processos microbianos (SILVA JÚNIOR; SIQUEIRA, 1997), fomentando, simultaneamente, a estrutura, a aeração e a capacidade de retenção de água. Atua ainda como regulador da temperatura do solo, retarda a fixação do $\mathrm{P}$ mineral e fornece produtos da decomposição orgânica que favorecem o desenvolvimento da planta (MURAISHI et al., 2010). A atividade dos microrganismos do solo, que sintetizam e decompõem a matéria orgânica, disponibiliza o nitrogênio, que, no solo, ocorre principalmente na forma orgânica (95\% de $\mathrm{N}$ total) (NOBILE et al., 2010).

Vale lembrar que a adubação mineral é, em várias situações, o insumo mais caro nos custos dos nutrientes que as fontes minerais, especialmente nos locais onde sua obtenção é facilitada (RODRIGUES; CASALI, 2000).

Konzen (2002) obteve redução de 85\% na aplicação de fertilizante químico em áreas de pastagens que receberam doses de dejeto líquido de suíno, enquanto Drumond (2003) concluiu que os nutrientes fornecidos através da dose de $200 \mathrm{~m}^{3}$ ha $^{-1}$ ano ${ }^{-1}$ de dejeto líquido de suíno, possibilitaram produção da ordem de $5.928 \mathrm{~kg}$ de matéria seca pré-pastejo do Cynodon sp cv Tifton 85, por ciclo de 28 dias.

Vários trabalhos também comprovam o efeito positivo da adubação orgânica sobre a produção e a qualidade de olerícolas como tomate, espinafre, rabanete, abobrinha italiana, cenoura, couve-flor e alface ( LUZ et al., 2004; VILLAS BOAS et al., 2004; YURI, et al. 2004). Souza et al. (2005) verificaram o aumento dos teores de proteína bruta, fósforo, potássio e de magnésio nas folhas de alface em função das doses de composto orgânico aplicadas.

Na cebola, maiores exigências hídricas ocorrem no período de formação dos bulbos (GARRIDO; CAIXETA, 1980). Costa Filho et al.(1995) relatam que níveis acima de 80\% de água disponível no solo proporcionaram maior peso médio de bulbos na cebola.

Gonçalves e Silva (2003) trabalharam com diversos adubos orgânicos e verificaram que a adubação orgânica pode substituir a adubação mineral na cultura da cebola. Quando em cebola são utilizados adubos orgânicos ricos em $\mathrm{N}$, tal como torta de mamona ou esterco de galinha, a adubação nitrogenada pode ser reduzida ou dispensada (FILGUEIRA, 2000).

O objetivo do trabalho foi analisar o efeito de diferentes níveis de irrigação no desenvolvimento e produção da cultura da cebola (Alium cepa L.) e também observar o efeito da adubação orgânica e mineral

\section{MATERIAL E MÉTODOS}

A presente pesquisa foi instalada na Faculdade de Ciências Agrárias e Veterinárias - UNESP Campus de Jaboticabal, em área experimental, a uma latitude de $21^{\circ} 15^{\prime} 22^{\prime}$ ' S, longitude de $48^{\circ} 18^{\prime} 58^{\prime \prime} \mathrm{W}$ 
e altitude de $590 \mathrm{~m}$. O delineamento experimental utilizado foi casualizado com 3 repetições num esquema em parcelas subdivididas, sendo 4 níveis de água considerados como parcela e 3 tipos de adubação comon subparcelas, sendo o solo da área experimental classificado de acordo com Andrioli e Centurion (1999), como Latossolo Roxo eutrófico A moderado, textura muito argilosa, relevo suave ondulado e ondulado (eutrustox). Os tratamentos constaram da associação entre níveis de água e tipos de adubação, conforme a Tabela 1.

Tabela 1. Esquema da associação entre níveis de água e tipos de adubação, caracterizando os tratamentos.

\begin{tabular}{lccc}
\hline Níveis de água & \multicolumn{3}{c}{ Adubação } \\
\cline { 2 - 4 } & AO & AM & SA \\
\hline W1 & W1AO & W1AM & W1SA \\
W2 & W2AO & W2AM & W2SA \\
W3 & W3AO & W3AM & W3SA \\
W4 & W4AO & W4AM & W4SA \\
\hline
\end{tabular}

W1 - Nível de água aplicada igual a 25\% da evapotranspiração; W2 - Nível de água aplicada a 50\% da evapotranspiração; W3 Nível de água aplicada igual a 100\% da evapotranspiração; W4-Nível de água aplicada igual a 150\% da evapotranspiração; AO Adubação orgânica (efluente de biodigestor); AM - Adubação mineral convencional (baseada na análise química do solo); AS Sem adubação.

A irrigação constou de 4 níveis de aplicação de água, em turnos de rega definidos às segundas e quintas feiras, baseados em uma evapotranspiração (ET) máxima de $4 \mathrm{~mm}$ diários, considerados no período de 35 - 70 dias após transplante. Na Tabela 2 estão apresentadas as porcentagens de água aplicada em relação ao período citado, e as lâminas d'água aplicadas em função dos tratamentos de níveis d'água, em relação ao percentual da evapotranspiração máxima, adotado para cada período. A água foi aplicada através de regadores com capacidade de 15 litros, simulando irrigação por aspersão.

Tabela 2. Evapotranspiração máxima (\%) considerada para cada período na cultura de cebola lâmina d'água aplicada em mm dia ${ }^{-1}$ em cada período, em função dos tratamentos de níveis de água.

\begin{tabular}{|c|c|c|c|}
\hline Dias após transplante & $\begin{array}{c}\text { Evapotranspiração } \\
\text { máxima }(\%)\end{array}$ & $\begin{array}{c}\text { Nível de água - }(\%) \text { da } \\
\text { evapotranspiração }\end{array}$ & $\begin{array}{l}\text { Lâmina d'água aplicada } \\
\qquad \mathrm{mm} \mathrm{dia}^{-1}\end{array}$ \\
\hline \multirow{4}{*}{$15-20$} & \multirow{4}{*}{ 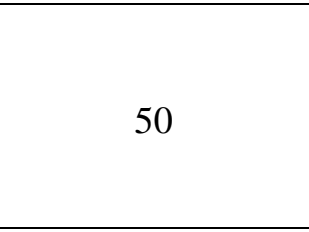 } & 25 & 0,5 \\
\hline & & 50 & 1,0 \\
\hline & & 100 & 2,0 \\
\hline & & 150 & 3,0 \\
\hline \multirow{4}{*}{$20-35$} & \multirow{4}{*}{80} & 25 & 0,8 \\
\hline & & 50 & 1,6 \\
\hline & & 100 & 3,2 \\
\hline & & 150 & 4,8 \\
\hline \multirow{4}{*}{$35-70$} & \multirow{4}{*}{100} & 25 & 1,0 \\
\hline & & 50 & 2,0 \\
\hline & & 100 & 4,0 \\
\hline & & 150 & 6,0 \\
\hline \multirow{4}{*}{$70-90$} & \multirow{4}{*}{70} & 25 & 0,7 \\
\hline & & 50 & 1,4 \\
\hline & & 100 & 2,8 \\
\hline & & 150 & 4,2 \\
\hline
\end{tabular}


O solo foi preparado com uma aração, seguida de destorroamento por enxada rotativa e preparo manual de 4 canteiros, com as seguintes dimensões: 1,00 metro de largura por 22,5 metros de comprimento e 10,5 metros entre canteiros. Sendo estes canteiros considerados como parcelas e as divisões com dimensões de 1,0 por 2,5 metros, considerados como subparcelas. A adubação de plantio constou de $22 \mathrm{~kg} \mathrm{ha}^{-1}$ de uréia, $1400 \mathrm{~kg} \mathrm{ha}^{-1}$ de superfosfato simples e $200 \mathrm{~kg} \mathrm{ha}^{-1}$ de cloreto de potássio, conforme com base na análise química do solo. Realizaram-se duas adubações de cobertura com uréia aos 29 e 44 dias aos o transplante. A adubação orgânica foi feita incorporando-se em toda a área da subparcela, efluente resultante da digestão anaeróbia de esterco de gado bovino em biodigestor, uma semana antes do transplante das mudas, na dose de $60 \mathrm{~m}^{3} \mathrm{ha}^{-1}$. Na Tabela 3, apresenta-se a análise química deste material.

Tabela 3. Dados das concentrações químicas do efluente utilizado no experimento.

\begin{tabular}{|c|c|c|c|c|c|c|c|c|}
\hline \multirow{3}{*}{$\begin{array}{c}\text { Sólidos Totais } \\
\begin{array}{c}\text {--- } \% \text {--- } \\
5,6\end{array}\end{array}$} & MO & $\mathrm{C}$ & $\mathrm{N}$ & $\mathrm{P}$ & K & $\mathrm{Ca}$ & $\mathrm{Mg}$ & $\mathrm{S}$ \\
\hline & \multicolumn{8}{|c|}{ - } \\
\hline & 68,81 & 39,91 & 1,97 & 1,14 & 2,69 & 2,53 & 0,77 & 0,51 \\
\hline $\mathrm{Fe}$ & $\mathrm{Cu}$ & $\mathrm{Mn}$ & & & $\mathrm{Zn}$ & & & $\mathrm{C} / \mathrm{N}$ \\
\hline 39,05 & 7,25 & 380 & & & 540 & & & 20,28 \\
\hline
\end{tabular}

MO- Matéria Orgânica; C-Carbono; N-Nitrogênio; P-Fósforo; K-Potássio; Ca-Cálcio; Mg-Magnésio; S-Enxofre; Fé-Ferro; CuCobre; Mn-Manganês; B-Boro; Zn-Zinco; pH-Potencial Hidrogeniônico ; C/N-Relação Carbono Nitrogênio

Semeou-se em canteiros especiais, sementes de cebola, cultivar PIRALOPES, segundo técnicas convencionais de formação de mudas de cebola. O transplante foi realizado manualmente quando as plantas alcançaram aproximadamente $18 \mathrm{~cm}$ de altura. Selecionando-se as mudas mais uniformes quanto a tamanho e sanidade, que foram transplantadas no espaçamento médio de $30 \mathrm{~cm}$ entre linhas e $8 \mathrm{~cm}$ entre plantas, perfazendo o total de 8 linhas de plantas por divisão (subparcelas). O controle de plantas daninhas foi feito manualmente e periodicamente nos canteiros, mantendo os mesmos sempre limpos durante o decorrer do ensaio. Foram feitas pulverizações preventivas, não ocorrendo nenhuma doença durante o decorrer do ensaio. A colheita teve início aos 110 dias após o transplante, prolongando-se por mais 17 dias até que aproximadamente $95 \%$ das plantas possuíam o bulbo com o tamanho máximo. Foram realizadas 5 medições com régua de $60 \mathrm{~cm}$, a qual era utilizada para medir a altura em relação à maior folha da planta em oito plantas por subparcela. Foram colhidas cinco fileiras em cada subparcela. A cura das cebolas foi feita sob um galpão seco e bem ventilado, onde as plantas inteiras permaneceram durante uma semana após a colheita. Posteriormente foram encaminhadas ao laboratório de Departamento de Engenharia Rural da FCAV/UNESP, a fim de se realizar a poda das raízes e da parte foliar. Após a colheita e cura dos bulbos, foi feita separação de 10 bulbos, os quais eram de tamanho médio, representativo de cada subparcela. Em seguida foi feita a medição do diâmetro dos bulbos, utilizando-se paquímetro com precisão de 0,01 mm, obtendo-se o valor do diâmetro médio por subparcela. Realizou-se a medida da massa de 20 bulbos por subparcela e obteve-se a massa média por planta. A massa de bulbos obtida nessas 5 linhas foi extrapolada para a produtividade no hectare. A avaliação do potencial matricial do solo foi realizada por meio de tensiômetros instalados a $15 \mathrm{~cm}$ de profundidade, num total de 30, distribuídos ao acaso entre as 36 subparcelas. As medidas foram realizadas medindo-se a altura da coluna de mercúrio a partir da superfície do mercúrio do reservatório. 


\section{RESULTADOS E DISCUSSÃO}

Os dados relativos à altura média de plantas de cebola estão representados na Tabela 4. Observase que o desenvolvimento das plantas foi melhor no tratamento com adubação mineral, seguido pelo tratamento com adubação orgânica e, por último, a testemunha que não se adubou. Esta diferença foi bem nítida e ocorreu em todos os níveis de água aplicados. Quanto maior a quantidade de água aplicada, maior a altura das plantas, em todas as adubações adotadas.

Tabela 4. Altura média das plantas $(\mathrm{cm})$, para a adubação dentro de cada nível de água.

\begin{tabular}{|c|c|c|c|c|c|c|}
\hline \multirow{2}{*}{\multicolumn{2}{|c|}{ Tratamento }} & \multicolumn{5}{|c|}{ Dias após o transplante } \\
\hline & & 33 & 47 & 61 & 75 & 90 \\
\hline $\mathrm{AM}$ & & 27,10 & 36,93 & 45,76 & 50,13 & 52,56 \\
\hline W1 & $\mathrm{AO}$ & 23,76 & 29,66 & 37,00 & 41,53 & 45,93 \\
\hline SA & & 22,53 & 26,70 & 36,23 & 39,20 & 44,76 \\
\hline $\mathrm{AM}$ & & 28,66 & 40,76 & 46,56 & 52,80 & 55,53 \\
\hline W2 & $\mathrm{AO}$ & 27,20 & 36,40 & 40,53 & 46,70 & 49,56 \\
\hline SA & & 26,10 & 34,40 & 39,36 & 44,36 & 47,90 \\
\hline $\mathrm{AM}$ & & 30,06 & 42,60 & 47,83 & 53,46 & 56,76 \\
\hline W3 & $\mathrm{AO}$ & 27,86 & 37,10 & 42,96 & 47,34 & 52,63 \\
\hline SA & & 26,90 & 35,16 & 40,13 & 45,12 & 49,38 \\
\hline AM & & 32,26 & 46,39 & 52,10 & 59,37 & 62,33 \\
\hline W4 & $\mathrm{AO}$ & 29,23 & 41,50 & 47,36 & 53,18 & 57,86 \\
\hline SA & & 27,75 & 38,20 & 43,16 & 48,30 & 52,45 \\
\hline
\end{tabular}

W1- nível de água aplicada igual a 25\% da evapotranspiração; W2- nível de água aplicada igual a 50\% da evapotranspiração; W3nível de água aplicada igual a 100\% da evapotranspiração; W4- nível de água aplicada igual a 150\% da evapotranspiração; AMadubação mineral (convencional); AO- adubação orgânica (efluente de biodigestor); AS- Sem adubação

Na Tabela 5, estão representados os dados médios do diâmetro de bulbos de cebola, com os níveis de significância estatística. Analisadas pelo teste de Tukey a 5\% de probabilidade.

Tabela 5. Valores médios de diâmetro de 10 bulbos (cm).

\begin{tabular}{lccc}
\hline Níveis de água & Média & Adubações & Média \\
\hline W4 & $6,72 \mathrm{a}$ & AM & $6,18 \mathrm{a}$ \\
W3 & $6,36 \mathrm{a}$ & AO & $5,89 \mathrm{ab}$ \\
W2 & $5,21 \mathrm{~b}$ & SA & $5,52 \mathrm{~b}$ \\
W1 & $5,17 \mathrm{~b}$ & & \\
\hline D.M.S. (5\%) & 0,91 & & 0,40 \\
\hline
\end{tabular}

Verificou-se que as médias dos diâmetros dos bulbos das plantas pertencentes aos níveis W1 e W2 não diferiram estatisticamente entre si, o mesmo acontecendo com os níveis $\mathrm{W} 3 \mathrm{e} \mathrm{W} 4$, formando, desta forma, dois grupos distintos, com diferença estatística entre ambos. Assim, as maiores quantidades de 
água proporcionaram maiores valores de diâmetro de bulbos.

Os dados médios de produtividade estão apresentados na Tabela 6. O peso total de bulbos não diferiu significativamente entre os tratamentos referentes aos níveis de água W3 e W4, o mesmo ocorrendo entre os tratamentos $\mathrm{W} 1$ e W2, mantendo os mesmos grupos com a mesma tendência da variável diâmetro do bulbo. Os tratamentos que receberam mais água (W3 e W4) foram superiores aos tratamentos referentes aos níveis de água W1 e W2. O que está de acordo com os resultados encontrados por Costa Filho et al., (1995), onde níveis acima de 80\% de água disponível no solo proporcionaram maior peso médio de bulbos na cebola.

As médias de produção para a adubação mineral e orgânica não diferiram entre si. Isto sugere que a adubação orgânica na dose de 60 m³/ha poderia substituir a adubação mineral. Gonçalves e Silva (2003) também constataram que a adubação orgânica pode substituir a adubação mineral na cultura da cebola. Resultados semelhantes foram obtidos para outras olerícolas (LUZ et al., 2004; VILLAS BOAS et al., 2004; YURI, et al. 2004).

Tabela 6. Valores médios de peso de bulbo em $\mathrm{g} \mathrm{planta}^{-1} \mathrm{e} \mathrm{t} \mathrm{ha}^{-1}$ (Tukey a 5\%)

\begin{tabular}{lccccc}
\hline \multicolumn{3}{c}{ Níveis de água } & \multicolumn{3}{c}{ Adubações } \\
\hline W4 & g planta $^{-1}$ & $\mathrm{t} \mathrm{ha}^{-1}$ & & g planta $^{-1}$ & t ha $^{-1}$ \\
W3 & $145,57 \mathrm{a}$ & $30,90 \mathrm{a}$ & AM & $115,40 \mathrm{a}$ & $23,75 \mathrm{a}$ \\
W2 & $121,72 \mathrm{a}$ & $24,95 \mathrm{a}$ & AO & $104,08 \mathrm{ab}$ & $21,67 \mathrm{a}$ \\
W1 & $72,79 \mathrm{~b}$ & $14,18 \mathrm{~b}$ & SA & $90,01 \mathrm{~b}$ & $17,70 \mathrm{~b}$ \\
\hline D.M.S. (5\%) & $72,58 \mathrm{~b}$ & $14,13 \mathrm{~b}$ & & & \\
\hline
\end{tabular}

Quanto ao potencial matricial, observa-se que na Tabela 7 o tratamento cultivado com adubação orgânica manteve o solo mais úmido, apresentando dados superiores às outras adubações.

A conservação do nível de água mais elevado no solo pode ser explicado pela capacidade da matéria orgânica em absorver água, melhorando a relação entre macro e microporos do solo. Segundo Bahia Filho et al., (1983) e Silva Júnior ; Siqueira (1997), resíduos orgânicos, decompostos, ativam os processos microbianos, fomentando simultaneamente, a estrutura, a aeração e a capacidade de retenção de água.

Tabela 7. Potencial matricial médio da água no solo durante a fase de formação de bulbos $(15 \mathrm{~cm}$ de profundidade).

(Continua)

\begin{tabular}{lcccccccc}
\hline \multirow{2}{*}{ Tratamento } & \multicolumn{7}{c}{ Dias após transplante } \\
\cline { 2 - 8 } & 40 & 45 & 50 & 55 & 60 & 65 & 70 & 75 \\
\hline W1 & $-91,0$ & $-113,4$ & $-180,7$ & $-260,7$ & $-520,2$ & $-622,2$ & $-781,2$ & $-801,4$ \\
AM/W2 & $-82,4$ & $-103,2$ & $-163,9$ & $-274,3$ & $-511,6$ & $-602,3$ & $-761,3$ & $-781,3$ \\
W3 & $-64,2$ & $-81,3$ & $-136,3$ & $-191,2$ & $-381,2$ & $-417,7$ & $-553,8$ & $-561,3$ \\
W4 & $-61,3$ & $-77,7$ & $-123,7$ & $-186,4$ & $-351,2$ & $-464,2$ & $-532,7$ & $-537,8$ \\
\hline W1 & $-90,5$ & $-108,7$ & $-176,4$ & $-251,7$ & $-516,4$ & $-581,4$ & $-719,3$ & $-794,7$ \\
AO/W2 & $-76,7$ & $-101,4$ & $-159,4$ & $-249,8$ & $-452,6$ & $-581,2$ & $-691,7$ & $-707,9$ \\
W3 & $-61,3$ & $-79,6$ & $-129,4$ & $-181,7$ & $-356,7$ & $-457,9$ & $-499,9$ & $-504,3$ \\
W4 & $-59,3$ & $-74,2$ & $-121,2$ & $-177,2$ & $-343,4$ & $-441,3$ & $-494,7$ & $-499,7$ \\
\hline \multicolumn{7}{c}{} \\
\hline
\end{tabular}


Tabela 7. Potencial matricial médio da água no solo durante a fase de formação de bulbos $(15 \mathrm{~cm}$ de profundidade).

(Conclusão)

\begin{tabular}{lllllllll} 
W1 & $-95,2$ & $-121,7$ & $-192,3$ & $-310,4$ & $-600,3$ & $-750,3$ & $-862,0$ & $-826,2$ \\
SA/W2 & $-91,3$ & $-117,3$ & $-172,6$ & $-278,6$ & $-499,1$ & $-643,3$ & $-774,2$ & $-819,8$ \\
W3 & $-79,3$ & $-92,7$ & $-147,7$ & $-201,4$ & $-381,5$ & $-499,3$ & $-591,3$ & $-617,8$ \\
W4 & $-73,4$ & $-79,9$ & $-135,1$ & $-199,4$ & $-396,4$ & $-481,4$ & $-572,4$ & $-571,7$ \\
\hline
\end{tabular}

Dias em que a cultura foi irrigada; W1- nível de água aplicada igual a 25\% da evapotranspiração; W2- nível de água aplicada igual a 50\% da evapotranspiração; W3- nível de água aplicada igual a 100\% da evapotranspiração; W4- nível de água aplicada igual a 150\% da evapotranspiração; AM- adubação mineral (convencional); AO- adubação orgânica (efluente de biodigestor); AS- Sem adubação

\section{CONCLUSÃO}

As plantas apresentaram maior crescimento em altura no tratamento com adubação mineral, seguido pelo de adubação orgânica com efluente de origem bovina para todos os níveis de água aplicados; entre os níveis de água, a aplicação de 100 e 150\% da evapotranspiração máxima, resultou em valores maiores de crescimento em altura.

O diâmetro médio dos bulbos não variou com o tipo de adubação. No entanto, foi maior para os dois maiores níveis de água aplicados.

A produtividade de bulbo, por planta ou hectare, não variou com o tipo de adubação, mas foi maior para os dois maiores níveis de água aplicados.

A incorporação de material orgânico ao solo através da aplicação de efluente de biodigestor proporcionou maiores valores de potencial matricial do solo, quando comparados com os obtidos na adubação mineral.

A adubação mineral da cebola pode ser substituída pela adubação orgânica com efluente de origem bovina, e os níveis correspondentes a 100 e $150 \%$ da evapotranspiração máxima considerada, resultaram melhores valores de produtividade de bulbos de cebola por planta e por hectare.

\section{REFERÊNCIAS}

ANDRIOLI, I.; CENTURION, J. F. Levantamento detalhado dos solos da Faculdade de Ciências Agrárias e Veterinárias de Jaboticabal. CONGRESSO BRASILEIRO DE CIÊNCIA DO SOLO,27, Brasília, 1999. Anais... Brasília, Sociedade Brasileira de Ciência do Solo, 1999. 32 p. (CD-ROOM).

COSTA FILHO, J. F.et al. Efeitos de níveis de umidade na produção de cebola (Allium cepa L). In: Seminário Nacional de Irrigação e Drenagem, 3., 1975 Fortaleza. Anais... Recife: INTER/DNOCS/ABD, n. 3, p. 104-110.

DRUMOND L. C. D. Aplicação de água residuária de suinocultura por aspersão em malha: desempenho hidráulico do sistema e produção de capim Tifton 85. 2003, 120p. Tese (Doutorado em Produção Vegetal). Universidade Estadual Paulista "Julio de Mesquita Filho" Faculdade de Ciências Agrárias e Veterinárias. Jaboticabal.

FACHINI,E; GALBIATTIJ. A;PAVANI,L.C. Níveis de irrigação e de composto de lixo orgânico na formação de mudas cítricas em casa de vegetação. Engenharia Agrícola, Jaboticabal, v.24, n.3, p.578-588, 2004.

FILGUEIRA, F. A. R. Novo manual de olericultura: agrotecnologia moderna na produção e comercialização de hortaliças. Viçosa: UFV, 2000. 402 p. 
GARRIDO, M. A. T.; CAIXETA, T. J. Irrigação em cultura de cebola. Informe Agropecuário, Belo Horizonte, v. 6, n. 62, p. 41-44, 1980.

GONÇALVES, P.A.S.; SILVA, C.R.S. Impacto da adubação orgânica sobre a incidência de tripes em cebola. Horticultura Brasileira, Brasília, v. 21, n. 3, p. 459-463. 2003.

LOPES, J. F. B., ANDRADE, E. M., CHAVES, L. C. G. Impacto da irrigação sobre os solos de perímetros irrigados na Bacia do Acaraú, Ceará, Brasil. Engenharia Agrícola, Jaboticabal, v. 28, n. 1, 2008.

KIEHL, E. J. Fertilizantes orgânicos. Agronômica Ceres. São Paulo. 429 p. 1985

KONZEN,E. A. Aproveitamento do adubo líquido da suinocultura na produção agropecuária. In: CONGRESSO NACIONALDE IRRIGAÇÃOEDRENAGEM, 2002, Uberlândia. Anais... Uberlândia: ABID, 2002.

LUZ, J.M. Q.etal. Composto orgânico de lixo urbano e vermiculita como substrato para produção de mudas de alface, tomate e couve-flor. Bioscience Journal v.20, p.67-74, 2004.

MARQUELLI, W. A.; SILVA, W. L. C.; MORETTI, C. L. Desenvolvimento de plantas, produção e qualidade de bulbos de alho sob condições de deficiência de água no solo. Horticultura Brasileira, Brasília, v. 20, n. 3, p. 470-473, setembro 2002.

MURAISHI, R. I.et al. Compostos orgânicos como substratos na formação de mudas de ipê-amarelo (tabebuia chrysotricha ( mart. ex. dc.) standl) irrigadas com água residuária. Engenharia Agrícola, Jaboticabal,v. 30, p. 1081-1088, 2010.

NOBILE, F. O. Uso de resíduos na agricultura. Revista UNIARA, Araraquara, v. 12, p. 169-184, 2009.

NOBILE, F. O.et al. Quantificação de macronutrientes no solo e em folhas de cana-de-açúcar em função de doses de resíduo da mineração de bauxita. Engenharia Agrícola, Jaboticabal, v. 30, p. 168-178, 2010.

NOBILE, F. O.; MURAISHI, R. I.; GALBIATTI, J. A. Distribuição de matéria orgânica em solo adubado com fertilizantes químicos e orgânicos. In: SIMPÓSIO CIENTÍFICO DOS PÓS-GRADUANDOS NO CENA-USP, 1. 2008, Piracicaba. Ciência: a questão água, 2008.

ONGLEY, E.D. Controle da poluição da água pelas atividades agrícolas. Tradução de GHEYI, H.R.; DAMASCENO, F.A.V.; BRITO, L. T. de L. Campina Grande: UFPB, 2000. 92 p. (Estudos FAO: Irrigação e Drenagem, 55).

RODRIGUES, E. T.; CASALI, V. W. D. Resposta da alface à adubação orgânica. I, - seleção de cultivares. Revista Ceres, v. 47, p. 461-467, 2000.

SILVA JÚNIOR, J. P. da; SIQUEIRA, J. O. Aplicação de formononetina sintética ao solo como estimulante da formação de micorriza no milho e na soja. Revista Brasileira de Fisiologia Vegetal, Brasília, v. 9, n. 1, p. 35-41, abr. 1997.

SOUZA, P. A.etal Características químicas de alface cultivada sob efeito residual da adubação com composto orgânico. Horticultura Brasileira, Brasília, v. 23, n.3, p. 754-757, 2005.

VILLAS BOAS, R. L.et al. Efeitos de doses e tipos de compostos orgânicos na produção de alface em dois solos sob ambiente protegido. Horticultura Brasileira, v. 22, p. 28-34, 2004.

YURI, J. E.et al. Efeito de composto orgânico sobre a produção e características comerciais de alface americana. Horticultura Brasileira, Brasília, v.22, n.1, p. 127-130, 2004. 